\title{
Integration between EVM and Risk Management: proposal of an automated framework
}

\author{
Anabela Tereso, Pedro Ribeiro, Manuel Cardoso \\ Centre ALGORITMI, University of Minho \\ Campus de Azurém, 4804-533 Guimarães, Portugal \\ anabelat@dps.uminho.pt, pmgar@dsi.uminho.pt, mpcardoso001@gmail.com
}

\begin{abstract}
The integration between Earned Value Management (EVM) and Project Risk Management immediately raises the question of the relationship between the two methods, even though EVM and project risk management share the same function in project management: promote the project success. At first glance it seems to be no further connection between these two methodologies, but the fundamentals of EVM are fully influenced by both risk management and risk analyses. This paper seeks to clarify the mechanisms of this function, and in which points they meet or affect each other, with reference to $P M B o K \AA$. The several techniques and methods are somewhat disperse and not always coherent. With the several assumptions resulting from the interconnection between the two methods, a framework of integration between them is proposed, as well as its practical implementation in Excel, resulting in a set of tools that can be useful in monitoring and controlling a project.
\end{abstract}

Keywords: Project Management, Project Control, Earned Value Management, Project Risk Management.

\section{Introduction}

The use of project management is relatively recent and has been motivated by the need for rapid and effective responses to the changing business environment [1]. One of the components of project management with the greatest need of development, due to increasing global competition and rapid technological growth, is project monitoring and control. Project monitoring and control allows to verify the state of the project during its execution and thus to conclude on its continuity within the parameters considered adequate. In case the parameters are outside the appropriate range, corrective measures can still be taken, which aim to promote the improvement of the state of the project and finally its conclusion with success, that is, within the objectives.

Another way to promote project's success is by risk management, but in this case minimizing the risk of not achieving the project objectives is achieved by creating early responses to the risks that may arise.

One of the methods used to monitor and control project status is EVM (Earned Value Management). In this method, the values estimated in the planning phase are compared with the project execution values, to determine project's state, and in this 
way create any adjustments that lead to project success. Given the increasing need for project monitoring and control techniques, one of the issues to be addressed is the possibility of using these two methodologies together to obtain additional monitoring and control information. This brings the need to investigate in detail the links between these two methodologies.

The two methodologies, having very different approaches, lead to the construction of a framework to summarize the links between EVM and Risk Management. After the link between the two methodologies is clarified, the idea of the possibility of transforming this information into something with practical utility in the monitoring and control of projects arises immediately.

Based on the above, the goals of this research were:

- Investigate the linkage between EVM and Risk Management;

- Build a framework for integrating the two methodologies;

- Use the framework to create project monitoring and control tools.

The integration between EVM and Risk Management is an area with several lines of research, mainly in the area of the introduction of uncertainty in EVM [2, 3].

The approach taken in this paper is similar to that proposed by the Association for Project Management (APM) [4], but based on the Project Management Body of Knowledge (PMBoK $\left.{ }^{\circledR}\right)$ from Project Management Institute (PMI) [5]. This type of approach is based on risk stratification, the different responses to each form of risk, and the introduction of the various risk components into the EVM methodology. This approach aims to include all forms of risk and risk responses and not just uncertainty.

\section{Literature Review}

Due to the increase in global competition and rapid technological development, many companies have begun to pay more attention to improving project control. This change took place both at the level of internal and external projects, which generated a growing interest in project monitoring and control techniques [6].

The unique nature of the projects creates uncertainty. This uncertainty generates several scenarios in which one or more project objectives may be affected by uncertain events or conditions, leading to the need to make risk assessment during planning. In PMBoK ${ }^{\circledR}$ this area of expertise is called project risk management [5].

On the other hand, when the project is already in execution, in the monitoring and control phase, it is necessary to have tools that allow the evaluation of the state of the project so that, in case of cost or time slippage, one can act and thus avoid or limit the problem. One of the methods recommended in PMBoK ${ }^{\circledR}$ is known as Earned Value Management (EVM) [5].

Traditional project cost management is done by simply analyzing costs over the project time, without an accurate measurement of the work that has actually been performed. We may be within budgeted cost but not have the expected work done. In the EVM methodology, the project performance is measured at each moment in relation to a cost baseline, which is constructed based on the costs of each task. As these are implemented, we have metrics that indicate whether the project is ahead or 
behind schedule, whether it is spending more or less than planned, and we have the possibility to predict the total final cost of the project [7].

The method is based on three values that allow obtaining control indices of the project and predictions of costs and deadlines at the end of the project, namely the Planned Value (PV), Actual Cost (AC) and Earned Value (EV). PV is the authorized budget assigned to scheduled work. AC is the realized cost incurred for the work performed on an activity during a specific time period. EV is the measure of work performed expressed in terms of the budget authorized for that work [5].

With these values we can evaluate Cost Variance $(\mathrm{CV}=\mathrm{EV}-\mathrm{AC})$, and Schedule Variance $(\mathrm{SV}=\mathrm{EV}-\mathrm{PV})$ or Cost Performance Index $(\mathrm{CPI}=\mathrm{EV} / \mathrm{AC})$ and Schedule Performance Index ( $\mathrm{SPI}=\mathrm{EV} / \mathrm{PV}$ ). If $\mathrm{CV}=0$ and $\mathrm{CPI}=1$, cost is as planned. If $\mathrm{CV}>0$ and $\mathrm{CPI}>1$, cost is under planned. If $\mathrm{CV}<0$ and $\mathrm{CPI}<1$, cost is over planned. The same reasoning can be done with the schedule, which may be ahead of schedule ( $\mathrm{SV}>0$ and $\mathrm{SPI}>1)$, on schedule $(\mathrm{SV}=0$ and $\mathrm{SPI}=1)$ or behind schedule $(\mathrm{SV}<0$ and $\mathrm{SPI}<1)[5]$.

Both PV and EV are based on the Performance Measurement Baseline (PMB), which is built from the Work Breakdown Structure (WBS) and its schedule in the planning phase. Therefore, in order for the EVM to be used as a realistic monitoring and control technique for project execution, the first step will be to understand and organize the project work during the planning phase.

At this planning stage it is necessary to elaborate the scope of the project using the WBS. Through the WBS the work can be organized into more manageable and executable elements, called work packages (or another element of the division of work considered appropriate for the project in consideration). Then the work has to be scheduled logically until all project work is included. Once the work is scheduled and the resources allocated, the scope, schedule and costs have to be integrated and recorded in a cost table, depending on the time/division of the work that is called PMB, like the one created during this research project (see Figure 1), adapted from PMI [8].

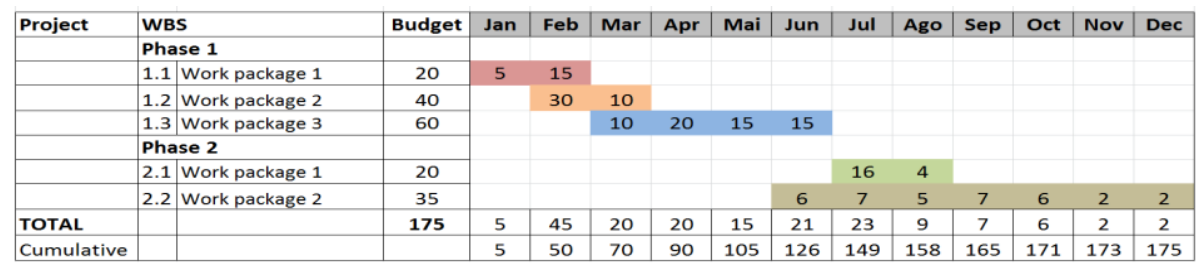

Fig. 1: PBM - Performance Measurement Baseline Adapted from PMI [8]

This plan, with the budget based on the work package per month, can be used to measure project performance. It is also necessary to have a technique that matches the physical progress of the work, in order to calculate the earned value of each work package, like the one created during this research project (see Figure 2), adapted from Anbari [9]. 


\begin{tabular}{|c|c|c|c|c|c|}
\hline \multirow[t]{3}{*}{ Project } & & \multirow[t]{2}{*}{ Budget } & \multirow[t]{2}{*}{ \% Complete } & \multirow[t]{2}{*}{ Earned Value } \\
\hline & \multicolumn{2}{|c|}{ Phase 1} & & & \\
\hline & 1.1 & Work package 1 & 20 & $100 \%$ & 20 \\
\hline & 1.2 & Work package 2 & 40 & $100 \%$ & 40 \\
\hline & 1.3 & Work package 3 & 60 & $100 \%$ & 60 \\
\hline & \multicolumn{2}{|c|}{ Phase 2} & & & \\
\hline & 2.1 & Work package 1 & 20 & $80 \%$ & 16 \\
\hline & 2.2 & Work package 2 & 35 & $60 \%$ & 21 \\
\hline TOTAL & & & 175 & & 157 \\
\hline
\end{tabular}

Fig. 2: Physical progress of work by the end of July Adapted from Anbari [9]

\section{EVM and Risk Management Integration Model Developed}

One of the objectives of this work was the creation of a model that seeks to integrate EVM with risk management, which will be presented in this section. In the first part the risk is stratified in order to create different responses to each type of risk and then is shown how each response can influence the EVM or how the EVM can be used in conjunction with the results of risk management. Practical methods for estimating management and contingency reserves are also described. A second part presents a proposal for a high-level framework, which is not intended to be exhaustive, but rather an example that can be further explored. As risk responses influence the different phases of the EVM methodology, the framework will also be a sequence that will allow each operation to be placed in its temporal position.

\subsection{Exposing Risk in the EVM Methodology}

Based on the approach of EVM to Risk management presented in PMBoK ${ }^{\circledR}$ [5], Practice Standard for Earned Value Management [10] and Practice Standard for Project Risk Management [11], the different types of risks were summarized in Figure 3.

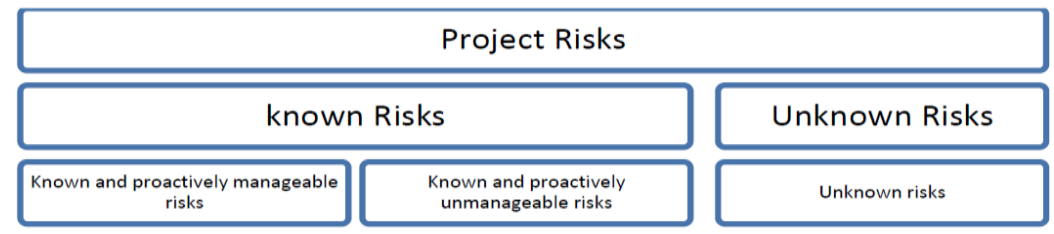

Fig. 3. Summary of project risks.

The steps to deal with the known and proactively manageable risks are:

- Risks identification, characterization and documentation.

- Qualitative analysis including the determination of probabilities and their impact on project objectives, leading to prioritization of risks. 
- Depending on the results of the impact on the project objectives, responses will be developed that include avoiding, transferring, mitigating and accepting the risk. Avoiding, transferring, and mitigating cause cost and time project changes.

Project changes brought about by the qualitative analysis translate into a more realistic Cost Baseline and therefore better EVM indices.

As for the known and proactively unmanageable risks, there is no way to treat them, either because it is impossible to eliminate the risk or because the risk has been accepted. This type of risk is guaranteed by a contingency reserve. Since this reserve will only be used in case the risk actually occurs, the EVM indexes are corrected whenever the risk occurs. This is because the contingency value is only considered in the Performance Measurement Baseline (PMB) if the risk materializes.

Unknown risks correspond to a part of the overall project risks and represent unspecified project uncertainty. These risks exist in all projects and since no measure can be taken, a management reserve is usually allocated to address this uncertainty.

\subsection{EVM and Risk Management Integration Framework}

In this section we propose a high level framework where risk management is integrated into the development of EVM (Figure 4). During the planning phase, the steps proposed are: develop the PMB based on the WBS and the schedule; analyze known risks; make the necessary modifications to the project; update PMB due to project modifications; with the global uncertainty, estimate the management reserve; include risk components that are known and proactively unmanageable; create in the control accounts the contingency reserves; approve the cost baseline; and obtain an estimate for the project budget where the risk is explicit and documented. Then, during control and monitoring phase, the steps proposed are: control management reserve through EVM; and control and check EVM indexes.

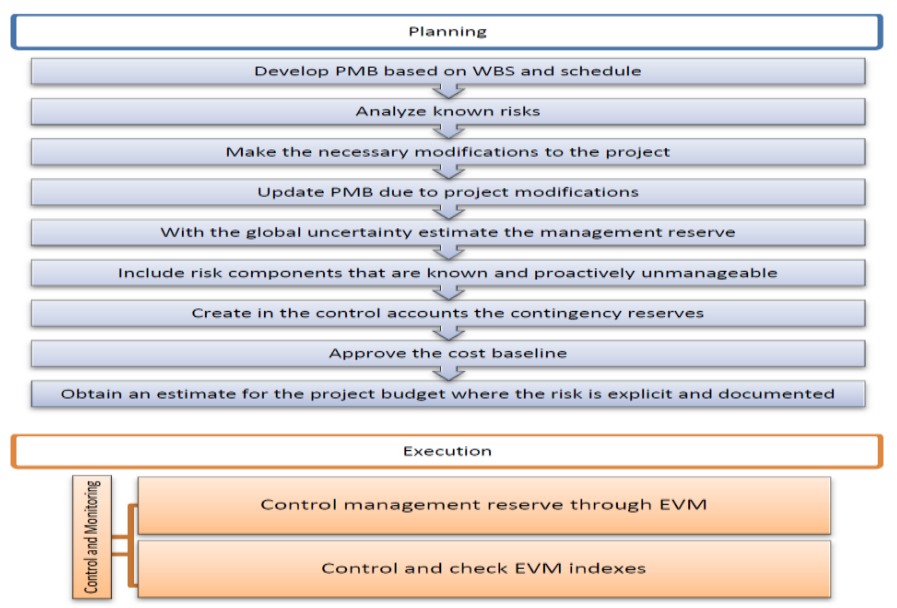

Fig. 4. EVM and risk management integration framework proposal. 


\section{Prototype for Project Monitoring and Control Support}

A prototype was created in Excel to demonstrate the application of the integration between EVM and risk management proposed. For the construction of these spreadsheets, MS Excel version 2013 was used with some subroutines written in Visual Basic for Applications.

As PMB is the basis of EVM, it will be the mechanism used to summarize the cost and time of the project. To create a PMB one needs to organize the work, schedule the work and establish the budget.

The PMB is a time-phased cost table based on the Work Breakdown Structure (WBS) and on the project schedule. See in Figure 5 an example of a PMB with the cumulative chart of planned costs or cumulative Planned Value (PV).

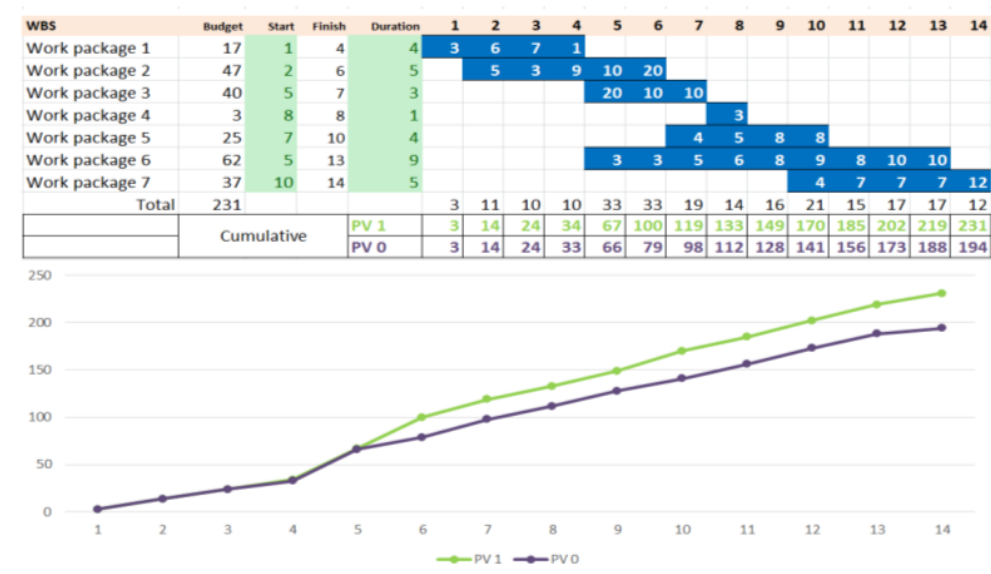

Fig. 5. Example of a PMB with cumulative PV

In the figure, PV 0 would be an initial version before the risk analysis in which the values were memorized for comparison with future versions. Approved changes to the project would result in PV 1. That is, after the risk analysis, responding to identifiable and treatable risks could result in a change to the PMB similar to the example shown.

To estimate the final value of the project taking into account the uncertainty we can construct a table in which the cost values of the various work elements are not fixed, but rather, a probabilistic distributions. Although the uncertainty is present, both in cost and time, in this model we only considered the cost uncertainty.

Using Monte Carlo simulation [12] with the cost model, we can obtain a probabilistic distribution of the possible cost results for the project. For this purpose we used@Risk, an add-in for Microsoft Excel from Palisade Corporation.

The three point estimation technique of PERT (Program Evaluation and Review Technique) was also used to improve the accuracy of the estimates for the costs of the activities [13].

The management reserve is the amount added to the total project budget to respond to the overall project risk and therefore should be dependent on uncertainty. 
The following is a practical example (Figure 6) where the management reserve is estimated from the 3 point technique in conjunction with the Monte Carlo simulation.

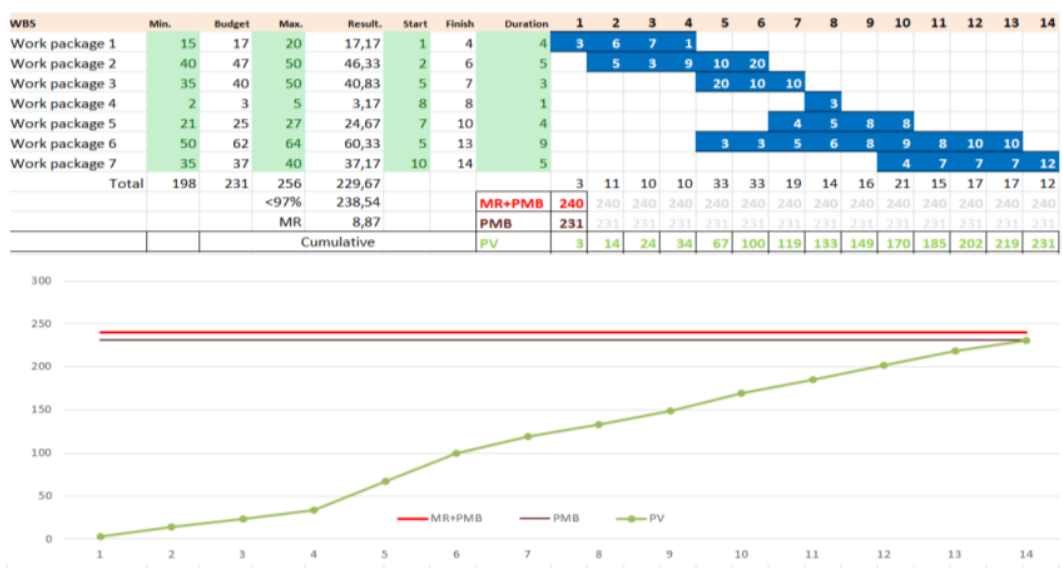

Fig. 6: Management Reserve and PMB

In this example the columns (Min), (Budget), and (Max) represent the pessimistic, most likely, and optimistic budget values respectively. The (Result) column represents the budget evaluated by Monte Carlo simulation for the work package. The distribution obtained using Monte Carlo simulation is shown in Figure 7.

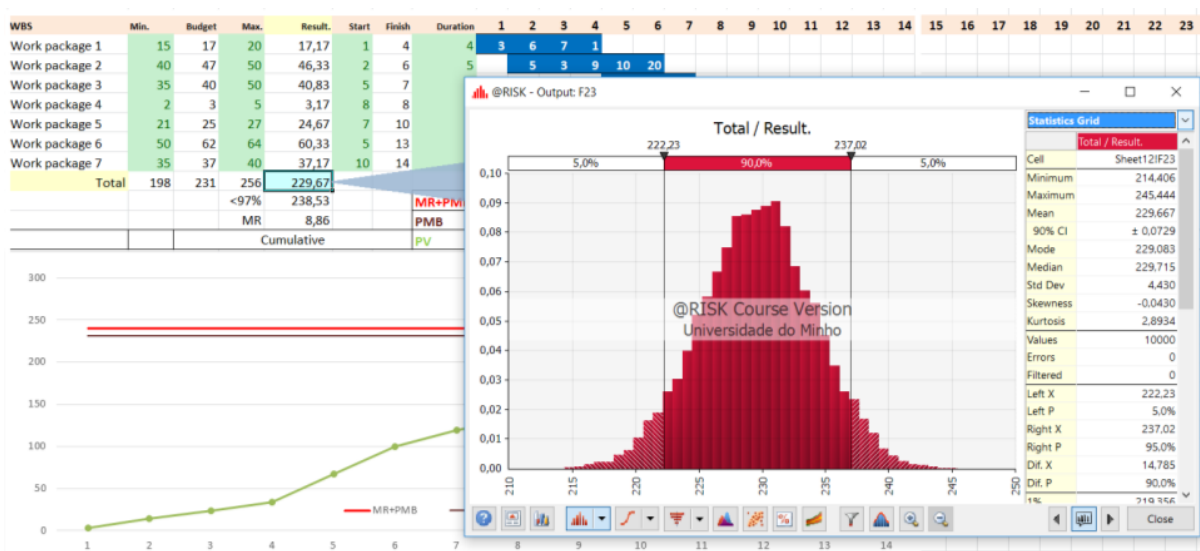

Fig. 7: Distribution obtained with the Monte Carlo simulation

The risks identified and not treated proactively are guaranteed by a contingency reserve. In the example presented, the table shown on Figure 8 serves to relate each element of the work to all risks identified and not treated proactively. Adding the exposure value to each risk gives the value of the total risk exposure for the work package. The total column shows the value of the contingency reserve for each work 
package. In Figure 9, the contingency value appears as a total added to the PMB. This figure shows the total value of the contingency reserve for the project, taking into account the risks registered. As the contingency reserve is only allocated in case the risk materializes, the amounts are only added to the PMB during the execution of the project. In practice, the figure allows controlling the total value of the reserve for the identified risks.

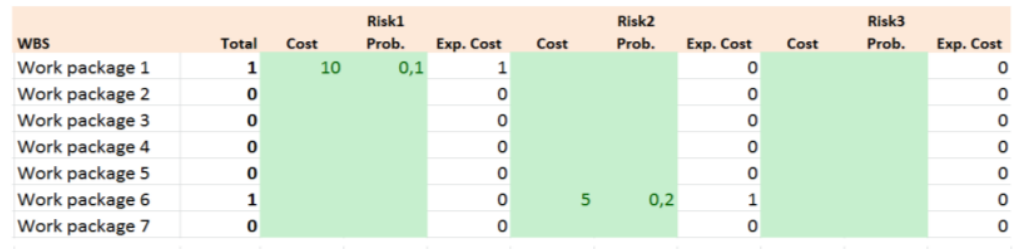

Fig. 8: Risk exposure table

The sum of the total value of the PMB with the total contingencies and with the management reserve results in a total for the project with the risks included.
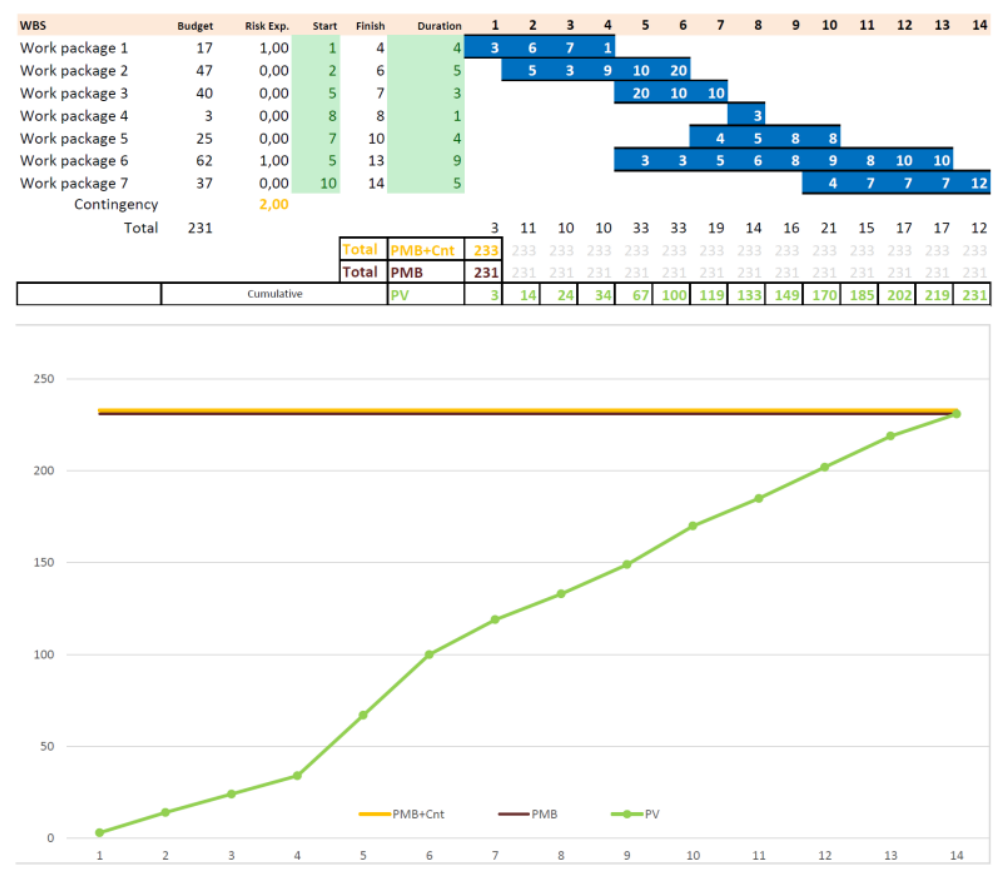

Fig. 9: Risks included on the PMB 


\section{Conclusions and Future Research}

The objective of this work was the proposal of a framework to support the monitoring and control of projects, based on the integration of EVM with risk management.

Risk management and EVM share the same role in project management; promote project success. However, each uses different means to achieve this result. Risk management seeks to anticipate possible responses to non-compliance with the objectives and EVM is intended to monitor the status of these objectives.

At first glance there seems to be no further connection between the two methodologies, but the fundamentals of EVM are fully influenced by both risk management and risk analysis. In $\mathrm{PMBoK} \AA$, integration is implicit and is not even referred to as "Integration between EVM and risk management", which makes necessary to clarify each risk component within the EVM methodology [5].

The framework presented in this paper integrates EVM and risk management. It was inspired on PMBoK ${ }^{\circledR}$ with influences of APM [4] and the integration proposed by Hillson [14].

The proposed integration is based on the EVM methodology, risk stratification and risk management methodology. Because EVM is based on the comparison of project execution values with planned values, introducing the components of risk or changes in planning produced by risk management, we get an EVM with more monitoring and control capabilities. On the other hand, risk is now recorded as one of the variables on which EVM depends. Finally, we state that the main characteristic of this model is the correction of the EVM performance indexes introduced by the risk management, and therefore the better quality on the information they provide.

Because EVM is dependent on other components of project management, such as WBS, timeline, cost accounting methods, a more advanced framework would need to include these components, making the process more complete. The same can be said of risk management, where for example the analysis of known risks requires a welldeveloped qualitative treatment.

In the prototype presented, the costs and schedule are manually placed on the PMB page. One possibility of extension would be the interconnection of the page with commercial software, such as MS Project.

Finally, in the current model, only the influences of the risk in cost were considered, but the time or schedule is also influenced. A natural extension would be the inclusion of time in the framework.

Acknowledgments. This work has been supported by COMPETE: POCI-01-0145FEDER-007043 and FCT - Fundação para a Ciência e Tecnologia within the Project Scope: UID/CEC/00319/2013. 


\section{References}

1. Kerzner, H., Project Management: A Systems Approach to Planning, Scheduling, and Controlling. 2009: John Wiley \& Sons.

2. Acebes, F., et al., A new approach for project control under uncertainty. Going back to the basics. International Journal of Project Management, 2014. 32(3): p. 423-434.

3. Pajares, J. and A. Paredes, An extension of the EVM analysis for project monitoring: The Cost Control Index and the Schedule Control Index. International Journal of Project Management, 2011. 29(5): p. 615-621.

4. APM, Interfacing Risk and Earned Value Management. 2008, Princes Risborough, Buckinghamshire: Association for Project Management.

5. PMI, A guide to the project management body of knowledge (PMBOK guide). 2013, Newtown Square, Pennsylvania: Project Management Institute, Inc. xxi, 589 pages.

6. Kim, E., W. Wells, and M. Duffey, A model for effective implementation of Earned Value Management methodology. International Journal of Project Management, 2003. 21(5): p. 375-382.

7. Fleming, Q. and J. Koppelman, Earned value project management. 2010, Newtown Square, Pennsylvania: Project Management Institute. viii, $231 \mathrm{p}$.

8. PMI, Practice standard for earned value management. 2005, Newtown Square, Pennsylvania: Project Management Institute, Inc. vii, $51 \mathrm{p}$.

9. Anbari, F., Earned value project management method and extensions. Project Management Journal, 2003. 34(4): p. 12.

10. PMI, Practice standard for earned value management. 2011, Newtown Square, Pennsylvania: Project Management Institute, Inc. xiv, 153 p.

11. PMI, Practice standard for project risk management. 2009, Newtown Square, Pennsylvania: Project Management Institute, Inc. xi, 116 p.

12. Mooney, C.Z., Monte carlo simulation. Vol. 116. 1997: Sage Publications.

13. Moder, J.J. and C.R. Phillips, Project Management with CPM and PERT. 1964.

14. Hillson, D. Earned Value Management and Risk Management: A practical synergy. in PMI Global Congress 2004 - North America. 2004. Anaheim, California, USA: PMI. 